\title{
Protective effects of Ginger Essential Oil (GEO) against chemically-induced cutaneous inflammation
}

\author{
$\mathrm{Na} \mathrm{XU}{ }^{1}$, Hong LEI ${ }^{1 *}$ (D), Xiaole $\mathrm{LI}^{2}$, Qing WANG ${ }^{3}$, Mo LIU ${ }^{1}$, Mengxi WANG ${ }^{1}$
}

\begin{abstract}
The inhibitory effects of ginger essential oil (GEO) on chemically-induced cutaneous inflammation were investigated. Three kind of experimental murine models, such as xylene-induced ear edema model, carrageenan-induced paw edema model and 2,4-dinitrofluorobenzene (DNFB)-induced allergic contact dermatitis (ACD) model were exploited to evaluate the anti-inflammatory effect of GEO. Results showed that GEO lowered the ear swelling rate induced by xylene and decreased paw edema rate induced by carrageenan of mice with cutaneous inflammation significantly. Treatment with GEO significantly inhibited DNFB-induced ear swelling degree and rate, and alleviated the inflammatory symptoms of ear skin lesions of ACD model mice markedly. Treatment with GEO decreased the gene expression of the inflammatory cytokines of auricular tissues such as TLR-2, TLR-4, TNF- $\alpha$, IFN- $\gamma$, IL-1 $\beta$, IL-8, and increased the gene expression of cytokine IL- 4 significantly. In conclusion, GEO has anti-inflammatory and protective effect on chemically-induced cutaneous inflammation.
\end{abstract}

Keywords: Ginger Essential Oil (GEO); Allergic Contact Dermatitis (ACD); protective effect; inflammatory cytokines.

Practical Application: As the candidate of functional component for ameliorating skin inflammation.

\section{Introduction}

Ginger, the rhizome of Zingiber officinale Roscoe (Zingiberaceae), is the traditional kind of food materials worldwide, and it has been reported that its extracts presented some pharmacological activities. Ginger and its essential oil (GEO) have been reported to have various healthy properties and pharmacological effects, such as antioxidant, antimicrobial, antinociceptive, anti-emetic and anticancer activities (Huang et al., 1997; Shukla \& Singh, 2007; Malu et al., 2009; Jeena et al., 2014).

The prevalence of allergic dermatitis is an estimated $15-20 \%$ of the general population suffering from contact allergy. The pathogenesis of dermatitis is delayed-type hypersensitivity (DTH) reaction caused by repeated exposure to the haptens, such as 2,4-dinitrofluorobenzene (DNFB). Topical application of DNFB to the skin induced inflammatory responses, known as allergic contact dermatitis (ACD), by attracting inflammatory cells, increasing level of pro-inflammatory cytokines (Wang et al., 2015).

There are several immune modulators in nature and recently finding the candidates from natural products increase as they are assumed to be safer to be used. Some reports of in vivo studies have indicated that GEO had anti-inflammatory activity. Penna et al. (2003) reported that crude hydroalcoholic extract of Zingiber officinale had antiedematogenic activity and was able to reduce rat paw and skin edema induced by carrageenan and serotonin. Young et al. (2005) reported that 6 -gingerol produced an inhibition of paw edema induced by carrageenin, which suggested that 6-gingerol possessed analgesic and anti-inflammatory activities. However, little information is available about the effects of GEO on skin inflammation such as ACD in vivo studies, especially concerning inflammatory cytokines induced by DNFB challenge.

Therefore, the present study would explore the anti-inflammatory effects of GEO prepared by supercritical carbon dioxide extraction method on skin inflammation. Moreover, the mechanisms of anti-inflammatory activity would also be explored, concerning inflammatory cytokines induced by DNFB challenge. The present study would provide the experimental basis for application of GEO as the candidate of functional component for ameliorating skin inflammation.

\section{Materials and methods}

\subsection{Preparation of Ginger Essential Oil (GEO)}

Ginger essential oil (GEO) was prepared by supercritical carbon dioxide extraction combined with macroporous resin further purification method in our laboratory as previously described (Lei et al., 2016), and the percentage content of [6]-gingerol in GEO was $46.60 \%$ which was measured by HPLC, as [6]-Gingerol has been used as a marker substance of ginger. GEO was dissolved in anhydrous ethanol and was half diluted to the percentage concentration of [6]-gingerol $23.30 \%$. 


\subsection{Animals}

Healthy Kunming strain mice, weighing $20 \pm 2$ g, were supplied by Changzhou Cavens Experimental Animal Co., Ltd. (Jiangsu, China). They were housed in plastic cages and maintained under standard conditions (12-h light-dark cycle, $23-25^{\circ} \mathrm{C}, 35-60 \%$ humidity). Before and during the experiment, mice were fed with the normal laboratory pellet diet and water was freely available. After randomization into various groups, mice were acclimatized in the new environment for two days before initiation of the experiment. Animals were maintained in accordance with the guidelines and complied with the current ethical regulations for the care and use of laboratory animals of Nanjing University of Finance and Economics (Jiangsu, China), the number of the process approved by the Experimental Regulation Committee of Nanjing University of Finance and Economics for the animal experiments was NUFE-ERULA-2017-013, and all mice used in the experiment received humane care. We confirm that the experimental protocols were approved by Experimental Regulations Committee of Nanjing University of Finance and Economics.

\subsection{Main reagents}

Xylene and carrageenan were purchased from Guoyao Chemical Reagent Co., Ltd and Shanghai Lanji Scientific Co., Ltd (Shanghai, China), respectively. 2,4-dinitrofluorobenzene (DNFB) (>99.0\% purity) was purchased from Shanghai Chemical Agent Co., Ltd (Shanghai, China), which was diluted in the vehicle of acetone: olive oil (4:1) before use. Compound Dexamethasone Acetate ointment was purchased from China Sanju Medical \& Pharmaceutical Co., Ltd. RNA enzymes scavenger, trizol reagent, first strand cDNA synthesis kit, PCR amplification kit, agarose, $6 \times$ DNA loading buffer, DL Marker 2000 were from Shanghai Sangon Biotech Co., Ltd (Shanghai, China). RNAiso Plus kits were from TAKARA BIO Co., Ltd. and reverse transcription kits were from Promega Co., Ltd. PCR primers were synthesized by Shanghai Sangon Biotech Co., Ltd (Shanghai, China). All the other chemicals used in the experiment were of analytical grade supplied by commercial suppliers.

\subsection{Xylene-induced ear edema in mice}

A total of forty mice were used and were divided into four groups, each containing ten mice as follows: the model control; three treatment groups (given GEO high dose (concentration of [6]-gingerol 46.60\%), GEO low dose (concentration of [6]-gingerol $23.30 \%$ ), dexamethasone acetate cream (Dex) Ointment, respectively). Ear edema model was induced by dripping xylene 20ul on the surfaces of right ear of mice, while left ear was used as the normal control. Thirty minutes later, the ears of mice were treated with vehicle or the tested substances. One hour later, the mice were killed by decapitation and the ears were cut off and weighed. The degree of ear swelling was expressed based on the difference in weight between left untreated ear sections and right treated ear sections, which was calculated according to the following equation: swelling rate $(\%)=\left(\mathrm{W}_{1}-\mathrm{W}_{0}\right) / \mathrm{W}_{0} \times 100 \%$, Where $W_{1}$ is the weight of the right ear and $W_{0}$ is the weight of the left ear.

\subsection{Carrageenan-induced paw edema in mice}

A total of forty mice were divided into four groups and were treated as the above described. The paw edema model was induced by injection of carrageenan (dissolved in sterile normal saline, $1 \% \mathrm{w} / \mathrm{v}, 0.05 \mathrm{~mL}$ ) into the right hind paw of each mouse. After injection, the paws of mice were treatment with vehicle or the tested substances. The thickness of the paw was measured before and 1, 2, 3, 4 and $5 \mathrm{~h}$ after carrageenan injection using a screw micrometer. The degree of paw swelling was evaluated by the difference of the thickness of the right paw after and before injection of carrageenan. Edema rate was calculated using the equation: $\mathrm{T}(\%)=\left(\mathrm{T}_{\mathrm{h}}-\mathrm{T}_{0}\right) / \mathrm{T}_{0} \times 100 \%$, Where $\mathrm{T}_{\mathrm{h}}$ is the paw thickness after carrageenan injection and $\mathrm{T}_{0}$ is the initial paw thickness.

\subsection{DNFB-induced Allergic Contact Dermatitis (ACD) in mouse skin}

Allergic contact dermatitis was induced in ear skin according to the method (Gaffal et al., 2013) with slight modifications. On day 0 , the abdomen of each mouse was shaved using surgical clippers. 2, 4-dinitrofluorobenzene (DNFB) was diluted in the vehicle of acetone: olive oil (4: 1) immediately before use. On day 1 and day 2, the abdomen skin of mice was smeared with $\operatorname{DNFB}(0.5 \%, 50 \mu \mathrm{L})$ to induce sensitization. On day 7 , mice were challenged by cutaneous application of DNFB $(0.5 \%, 50 \mu \mathrm{L})$ on both sides of right ears, while the left ears were treated with the vehicle (acetone-olive oil $50 \mu \mathrm{L}$ ) as the control.

In the experiment a total of 50 mice were used and were divided into five groups, each containing 10 mice as follows: normal control; ACD model control; three treatment groups (given GEO high dose, GEO low dose or dexamethasone acetate cream (Dex)). Mice were cutaneously treated with GEO or Dex twice a day for two days (on day 8, day 9), just after being challenged with DNFB or vehicle.

Skin lesions of the right ears were observed and the scores of lesions were recorded at $12 \mathrm{~h}, 24 \mathrm{~h}$, and $36 \mathrm{~h}$ after being challenged by cutaneous application of DNFB. The score criteria of ear skin lesions was represented by "Erythema" and "Edema" levels. "Erythema free", "Mild erythema", "Moderate erythema without crusts", "Moderate erythema with mild crusts", "Severe erythema with severe crusts" was scored " $0,1,2,3,4$ ", respectively. "Edema free", "Mild edema", "Moderate edema", "Severe edema” was scored " $0,1,2,3$ ", respectively.

The ear swelling degree was evaluated by the difference of thickness between the left ear and right ear, which was measured with a digital vernier caliper at $24 \mathrm{~h}$ and $48 \mathrm{~h}$ after DNFB challenge.

After mice were killed, the rate of ear swelling was evaluated by the percentage difference of weight between the left ear and right ear, which was calculated according to the following equation: ear swelling rate $(\%)=\left(\mathrm{W}_{1}-\mathrm{W}_{0}\right) / \mathrm{W}_{0} \times 100 \%$, Where $\mathrm{W}_{1}$ is the weight of the right ear and $W_{0}$ is the weight of the left ear.

Histopathological changes of the ear skin tissues were observed under the light microscope. The ear skin specimens were preserved in $10 \%$ neutral formalin and were processed for 
paraffin embedding. Following standard micro-techniques, 5- $\mu \mathrm{m}$ sections of ear skin tissues were stained with alum haematoxylin and eosin for microscopic observation of histopathological changes $(200 \times)$.

Moreover, gene expression levels of Toll like receptor 2 (TLR-2), Toll like receptor 4 (TLR-4), tumor necrosis factor- $\alpha$ (TNF $\alpha)$, interferon- $\gamma($ IFN $\gamma)$, interleukin- $1 \beta$ (IL-1 $\beta)$, interleukin-4 (IL-4) and interleukin-8 (IL-8) of ear skin tissues were determined by reverse transcription polymerase chain reaction (RT-PCR). Total RNA of ear skin tissue was extracted with TRIzol and was reversely transcribed to synthesize cDNA with reverse transcriptase AMV. cDNA was amplified by PCR with specific primers and Taq polymerase. Standard PCR reaction was then performed on the synthesized cDNA with the model DNA template. Primers and the annealing temperature of objective genes and reference gene GAPDH were shown in Table 1 . The size of PCR products were $500 \mathrm{bp}$. The thermal cycle profile of TLR2 was: denaturation at $94{ }^{\circ} \mathrm{C}$ for $5 \mathrm{~min}, 30$ cycles (denaturation at $94{ }^{\circ} \mathrm{C}$ for $30 \mathrm{~s}$, annealing at $58^{\circ} \mathrm{C}$ for $60 \mathrm{~s}$ and extension at $72{ }^{\circ} \mathrm{C}$ for $60 \mathrm{~s}$ ) and final extension at $72^{\circ} \mathrm{C}$ for $5 \mathrm{~min}$. The thermal cycle profiles of TLR- 4 , TNF $\alpha$, IFN $\gamma$, IL- $1 \beta$, IL- 4 , IL- 8 and GAPDH were the same as those of TLR2 except the annealing temperature shown in Table 1. PCR products of objective genes and reference gene were then subjected to $1 \%$ agarose gel electrophoresis at $120 \mathrm{~V}$ for $30 \mathrm{~min}$ and were observed with UV illuminator. The gray shades of resulting bands of PCR products were evaluated by the electrophoretic image analysis system. The ratios of gray shade between objective genes and reference gene were then calculated.

\subsection{Statistical analysis}

Data were expressed as means \pm s.d. Statistical analysis was evaluated using SPSS 16.0 software by one-way analysis of variance, followed by the Student-Newman-Keuls test for multiple comparisons, which was used to evaluate the difference between two groups. $P<0.05$ was considered significant.

\section{Results and discussion}

\subsection{Effect of Ginger Essential Oil (GEO) on xylene-induced ear edema in mice}

Xylene caused severe irritation of right ears of the mice, leading to the symptoms of the acute inflammatory response such as congestion and edema of ear tissues. As shown in Figure 1, the ear swelling rate of the model group mice was significantly higher as compared with that of the treatment group. Treatment with GEO (high and low dose) and dexamethasone acetate (Dex) lowered the ear swelling rate significantly $(\mathrm{P}<0.01)$. This suggested that GEO has anti-inflammatory effect on xylene-induced ear edema in mice.

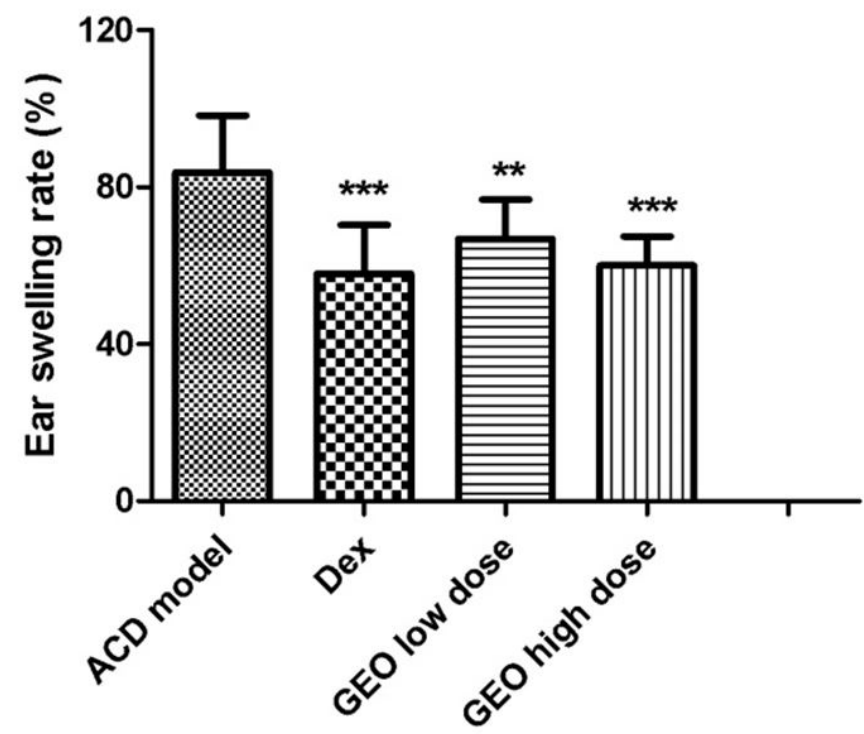

Figure 1. Effects of Ginger Essential Oil (GEO) on Xylene-induced ear edema in mice. Date are expressed as mean \pm S.D. $(n=10)$. Compared with ACD model group, ${ }^{* *} \mathrm{P}<0.01,{ }^{* *} \mathrm{P}<0.001$.

Table 1. Sequences of primers of objective genes and reference gene.

\begin{tabular}{|c|c|}
\hline Genes & Sequence of primers annealing temperature \\
\hline toll-like receptor-2 (TLR-2) sense & 5'-TTTGCTCCTGCGAACTCC-3’ $58^{\circ} \mathrm{C}$ \\
\hline TLR-2 antisense & 5'-GCCACGCCCACATCATTC-3' \\
\hline toll-like receptor-4 (TLR-4) sense & 5'-TTCAGAGCCGTTGGTGTATC-3' $58^{\circ} \mathrm{C}$ \\
\hline TLR- 4 antisense & 5’-CTCCCATTCCAGGTAGGTGT-3’ \\
\hline tumor necrosis factor- $\alpha$ (TNF- $\alpha$ ) sense & 5'-CCCAGAAAAGCAAGCAACCA-3' $58^{\circ} \mathrm{C}$ \\
\hline TNF- $\alpha$ antisense & 5’-CCTCGGGCCAGTGTATGAGA-3’ \\
\hline interferon- $\gamma($ IFN- $\gamma)$ sense & 5'-GCTCTGAGACAATGAACGCTAC-3' $58^{\circ} \mathrm{C}$ \\
\hline IFN- $\gamma$ antisense & 5’-GGACCTGTGGGTTGTTGA-3’ \\
\hline interleukin-1 $\beta$ (IL-1 $\beta$ ) sense & 5'AGCCCATCCTCTGTGACTC-3' $58^{\circ} \mathrm{C}$ \\
\hline IL-1 $\beta$ antisense & 5’-AAACTCCACTTTGCTCTTGAC-3’ \\
\hline interleukin-8 (IL-8) sense & 5'ACGCTGGCTTCTGACAACACTAGT-3' $60^{\circ} \mathrm{C}$ \\
\hline IL-8 antisense & 5’-CСTCTCTGTCCTGAGACGAGAAGG-3’' \\
\hline interleukin-4 (IL-4) sense & 5'-TGTCATCCTGCTCTTCTTTCT-3' $58^{\circ} \mathrm{C}$ \\
\hline IL-4 antisense & 5'-TTGGACTCATTCATGGTGC-3’' \\
\hline GAPDH sense & 5'-TGGAGAAACCTGCCAAGTATG-3' $58^{\circ} \mathrm{C}$ \\
\hline GAPDH antisense & 5'-CCCTGTTGCTGTAGCCGTAT-3' \\
\hline
\end{tabular}




\subsection{Effect of GEO on carrageenan-induced paw edema in mice}

Results of the anti-inflammatory effect of GEO on carrageenan-induced paw edema in mice were shown in Figure 2. There was a gradual increase in the thickness of paw edema at $1,2,3,4$ and $5 \mathrm{~h}$ after carrageenan injection. The paw edema rate of the model group mice was significantly higher as compared with that of the treatment group. Treatment with GEO (high and low dose) and dexamethasone acetate (Dex) decreased paw edema rate significantly $(\mathrm{P}<0.05$ or $\mathrm{P}<0.01)$. This indicated that GEO has anti-inflammatory effect on carrageenan-induced paw edema in mice.

\subsection{Effect of GEO on DNFB-induced Allergic Contact Dermatitis (ACD) mice}

GEO inhibited ear skin lesions in DNFB-induced ACD mice

The anti-inflammatory effect of GEO was assessed by the persistent skin inflammation model induced by topical application with the hapten DNFB. Obvious changes of the skin lesions were observed in the right ears of ACD models. Right ears of ACD model mice became swollen and edematous, erythema appeared, the skin of right ears became crusted and blood vessels of auricular skin dilated. Treatment with GEO could alleviate the inflammatory symptoms of right ears of ACD model mice markedly.

Moreover, the scores of ear skin lesions $12 \mathrm{~h}, 24 \mathrm{~h}$ and $36 \mathrm{~h}$ after DNFB challenge were shown in Figure 3. There is no significant difference of ear skin lesions in each group $12 \mathrm{~h}$ after the challenge. While $24 \mathrm{~h}$ and $36 \mathrm{~h}$ after the challenge, the scores of ear skin lesions of ACD mice increased significantly. Treatment with GEO (high and low dose) lowered the scores of ear skin lesions of ACD mice markedly as compared with those of the untreated mice. Treatment with dexamethasone acetate (Dex) also could lower the scores of ear skin lesions markedly. This suggested that GEO has inhibitory effect on ear skin lesions induced by DNFB challenge.

\section{GEO inhibited DNFB-induced ear swelling in mice}

Effect of GEO on DNFB-induced ear swelling degree of ACD mice was shown in Figure 4. Effect of GEO on the ear swelling rate of ACD mice was shown in Table 2. Ear swelling degree of ACD mice was severe $24 \mathrm{~h}$, $48 \mathrm{~h}$ after DNFB challenge. GEO (high and low dose) significantly inhibited the DNFB-induced ear swelling degree significantly, and moreover, the ear swelling rate was also inhibited by GEO $48 \mathrm{~h}$ after DNFB challenge $(p<0.01)$. Treatment with compound dexamethasone acetate cream (Dex) also could inhibit the ear swelling degree and swelling rate of ACD mice markedly.

\subsection{Histopathological observation}

Healthy auricular tissues were observed in normal group mice (Figure 5A). Compared with normal control, the auricular tissues became swollen, thick and edematous, moreover, congestion and the obvious infiltration of inflammatory cells were observed in the ACD model group mice (Figure 5B). Treatment with GEO

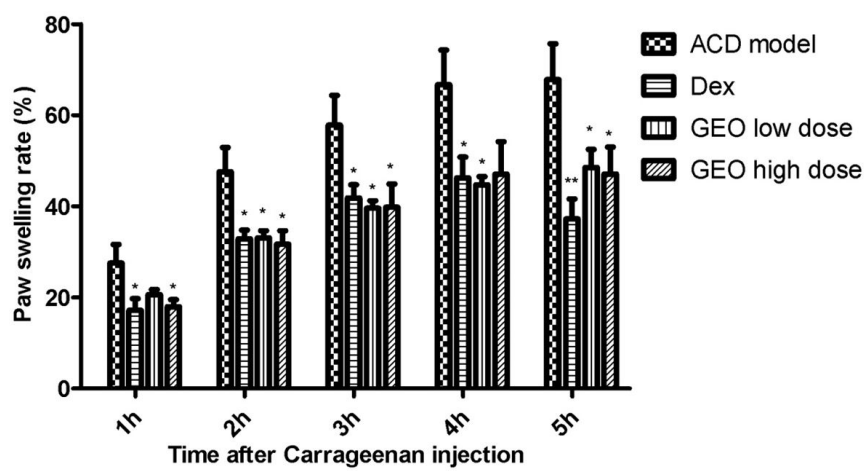

Figure 2. Effect of Ginger Essential Oil (GEO) on Carrageenan-induced paw edema in mice. Date are expressed as mean \pm S.D. $(n=10)$. Compared with ACD model group, ${ }^{\star} \mathrm{P}<0.05,{ }^{*} \mathrm{P}<0.01$.

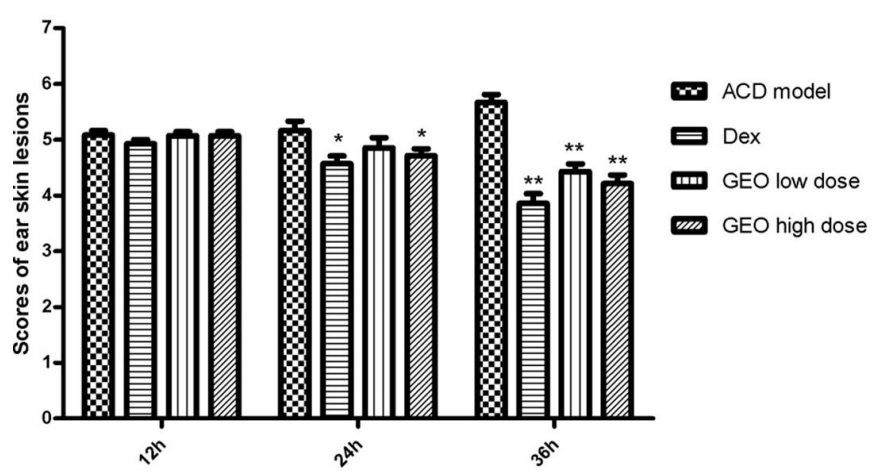

Figure 3. Effect of Ginger Essential Oil (GEO) on DNFB-induced ear skin lesions of ACD mice. Date are expressed as mean \pm S.D. $(n=10)$. Compared with ACD model group, ${ }^{\star} \mathrm{P}<0.05,{ }^{*} \mathrm{P}<0.01$.

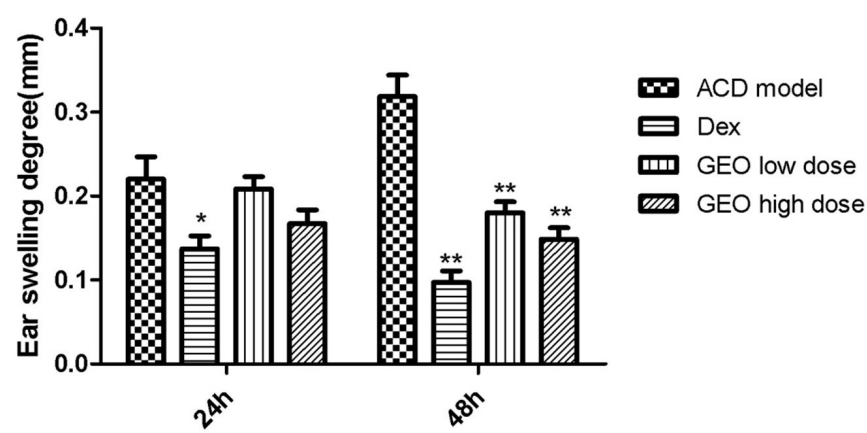

Figure 4. Effect of Ginger Essential Oil (GEO) on DNFB-induced ear swelling degree of ACD mice. Date are expressed as mean \pm S.D. $(n=10)$. Compared with ACD model group, ${ }^{\star} \mathrm{P}<0.05,{ }^{*} \mathrm{P}<0.01$.

Table 2. Effect of Ginger Essential Oil (GEO) on the ear swelling rate of ACD mice.

\begin{tabular}{cccc}
\hline Group & $\begin{array}{c}\text { Weight of left } \\
\text { ear }(\mathrm{mg})\end{array}$ & $\begin{array}{c}\text { Weight of right } \\
\text { ear }(\mathrm{mg})\end{array}$ & $\begin{array}{c}\text { Ear swelling } \\
\text { rate }(\%)\end{array}$ \\
\hline ACD model & $43.91 \pm 1.09$ & $72.69 \pm 1.87$ & $66.20 \pm 4.29$ \\
Dex & $37.79 \pm 0.87$ & $45.13 \pm 1.23$ & $19.67 \pm 2.82^{* * *}$ \\
GEO low dose & $40.68 \pm 1.08$ & $54.69 \pm 2.30$ & $34.40 \pm 4.16^{* * *}$ \\
GEO high dose & $39.61 \pm 1.36$ & $51.14 \pm 1.72$ & $29.26 \pm 1.72^{* * *}$ \\
\hline
\end{tabular}

Date are expressed as mean \pm S.D. $(n=10)$. Compared with ACD model group; ${ }^{* * *} \mathrm{P}<0.001$. 

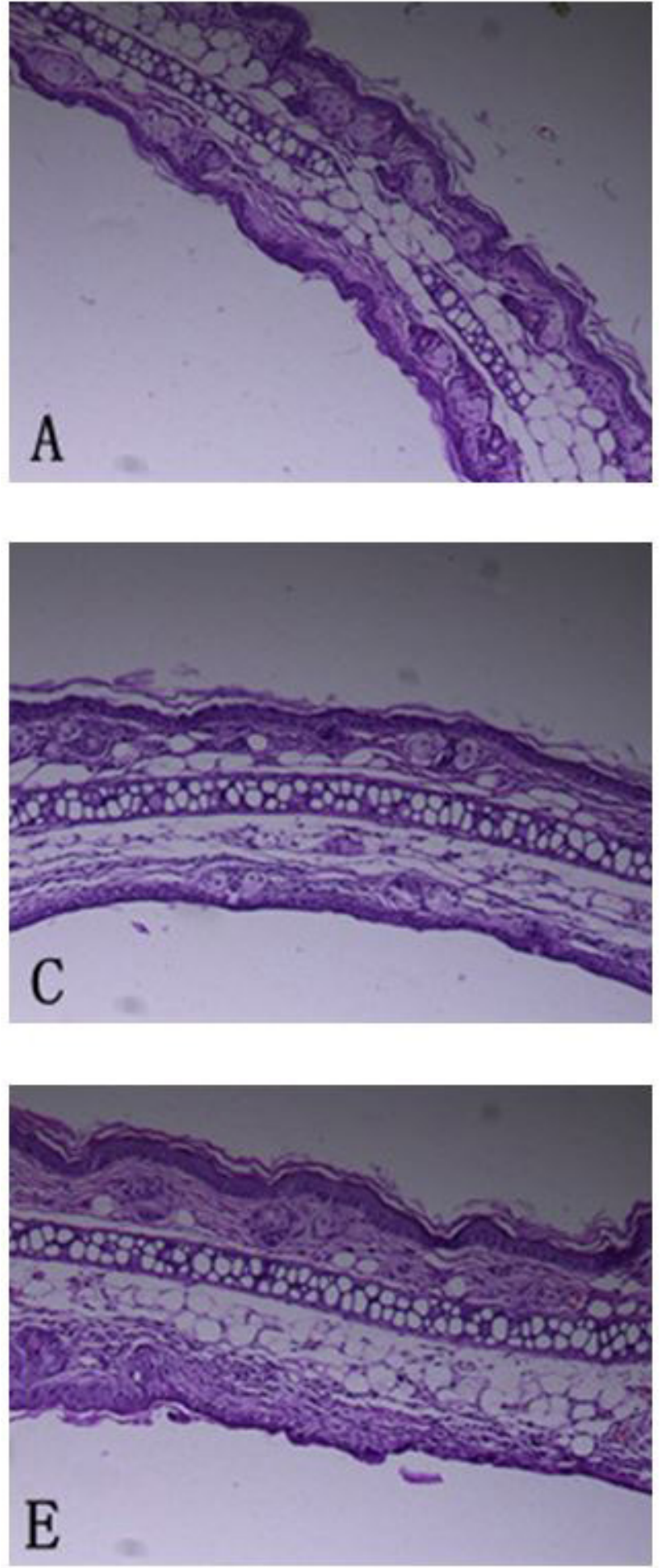

Figure 5. The histopathological observation of ear skin tissue of mice. (A) Normal group; (B) ACD Model group; (C) Dex group; (D) GEO low dose group; (E) GEO high dose group.

markedly reduced DNFB-induced thickening of dermis and local vascular dilatation, and ameliorated the destruction of auricular tissues of DNFB-induced ACD mice as compared with the untreated mice (Figure 5D, 5E). Treatment with dexamethasone acetate (Dex) also had the similar effects (Figure 5C). This suggested that GEO could ameliorate the destruction of auricular tissues of DNFB-induced ACD mice significantly.
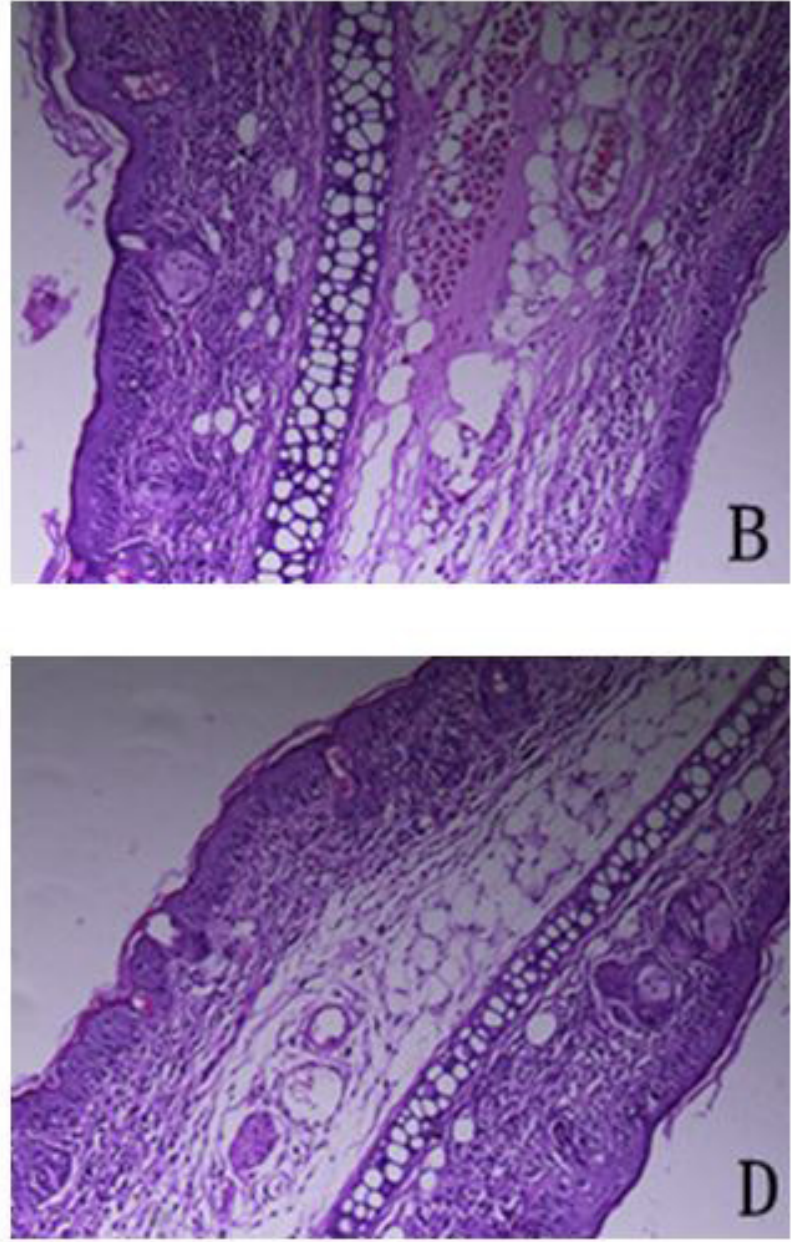

\subsection{Effect of GEO on gene expression of inflammatory cytokines of ear skin tissues}

Allergic contact dermatitis (ACD) is a kind of skin inflammatory reaction mediated and regulated by $\mathrm{T}$ lymphocytes and several cytokines (Akhtar et al., 2010). Toll-like receptors (TLRs) are the evolutionarily conserved transmembrane receptors which 
play a critical role in the innate immune system and acute inflammatory response (Medzhitov, 2011). Toll-like receptor-2 (TLR-2) is one of the most molecular expression of TLRs family members, widely distributed on surface of innate immune cells, and could recognize peptidoglycan and other ligands and then induce the production of inflammatory cytokines (Pan et al., 2012). TLR-4 activation increases monocyte chemoattractant protein and other chemokine expression, which is involved in monocyte aggregation and initiating inflammatory response (Ding et al., 2013). TLRs family had been previously shown to induce production of various inflammatory cytokines, such as $\mathrm{TNF}_{\alpha}$ and interleukins (Hausmann et al., 2002).

$\mathrm{TNF}_{\alpha}$ is one of the proinflammatory cytokines and could activate the macrophages and NK cells to promote their phagocytic and killing ability, and could also activate the endothelial cells to engender secretion of interleukin cytokines such as IL-1 $\beta$, IL-6, IL-8, which could promote the occurrence of local inflammation (D'Mello et al., 2009). Interferon $\gamma$ (IFN ${ }_{\gamma}$ ) is an important mediator of immune inflammatory response and the main effector cytokines concerning ACD, which is the most effective cytokines activating macrophagocytes and can regulate proliferation and differentiation of lymphocytes, regulating synthesis and secretion of various immunological cytokines (Zhou, 2009).

Interleukins play an important role in the inflammatory response such as activation and regulation of immune cells, proliferation and differentiation of T, B lymphocytes. IL- $1 \beta$ is mainly produced by activated mononuclear phagocytes, which is a potent proinflammatory cytokine and plays an important role in neutrophil chemotaxis and activation. IL-4 is a kind of anti-inflammatory cytokines and an important immunological regulators, which has immunomodulatory effects on $\mathrm{T}$ and $\mathrm{B}$ lymphocytes and macrophages, and play an important role in the proliferation, differentiation and functional regulation of $\mathrm{T}$ cells (Li et al., 2010). IL-8 is mainly produced by monocytes, endothelial cells and macrophages, which is an important proinflammatory cytokine and could attract neutrophils, macrophages and other inflammatory cells to migrate to inflammatory foci, activating the inflammatory response (Wang et al., 2016). Therefore, the present study would explore the anti-inflammatory mechanism of GEO on ACD concerning these inflammatory cytokines stated above.

Gene expression of the representative inflammatory cytokines (TLR-2, TLR-4, TNF- $\alpha$, IFN- $\gamma$, IL- $1 \beta$, IL-8 and IL-4) of auricular tissues were shown in Figure 6. Compared with the normal group, gene expression levels of the inflammatory cytokines TLR-2, TLR-4, TNF- $\alpha$, IFN- $\gamma$, IL- $1 \beta$, IL-8 were significantly higher in the ear tissues of ACD model group $(\mathrm{P}<0.01)$, while the gene expression levels of the cytokines IL-4 were significantly lower in the model group $(\mathrm{P}<0.01)$. Treatment with GEO markedly decreased the gene expression of the cytokines TLR-2, TLR-4, TNF- $\alpha$, IFN- $\gamma$, IL- $1 \beta$, IL- 8 significantly $(P<0.01)$, and increased the gene expression of the cytokine IL- 4 significantly $(\mathrm{P}<0.01)$. These suggested that the anti-ACD effect of GEO were related to its inhibiting production of inflammatory cytokines induced by DNFB.
(A)

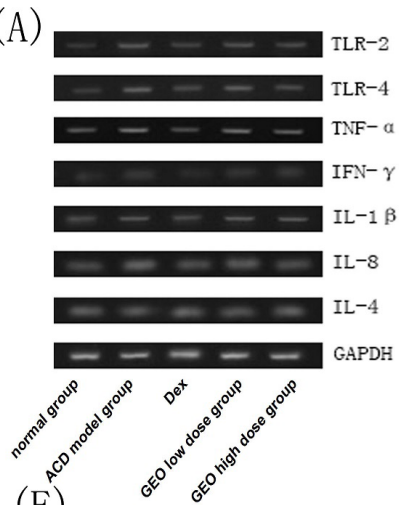

(E)

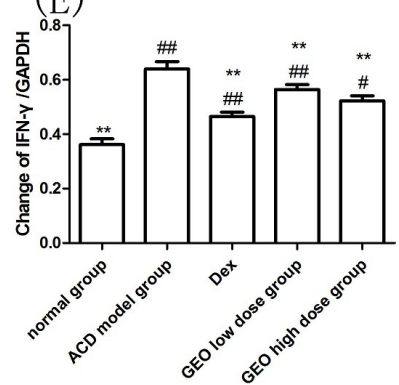

(B)

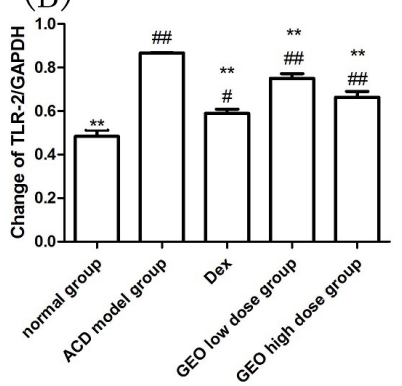

(F)

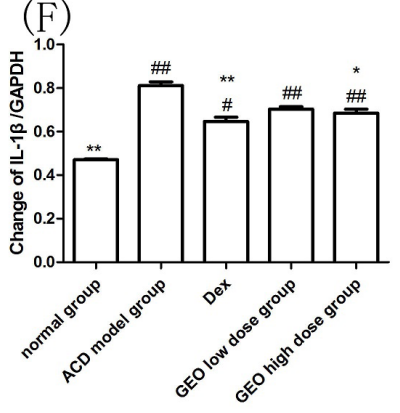

(C)

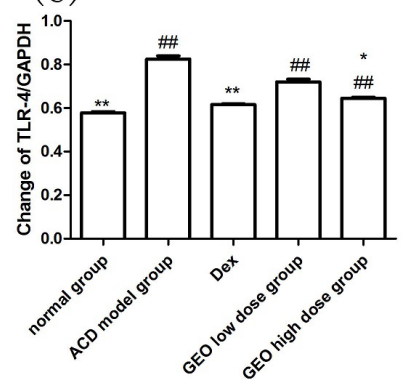

$(G)$

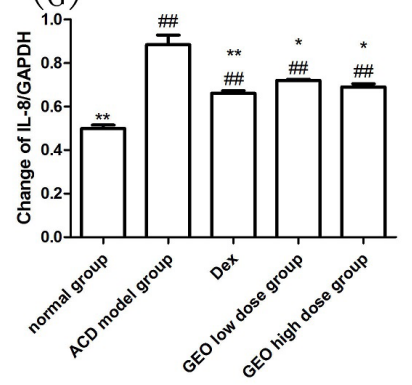

(D)
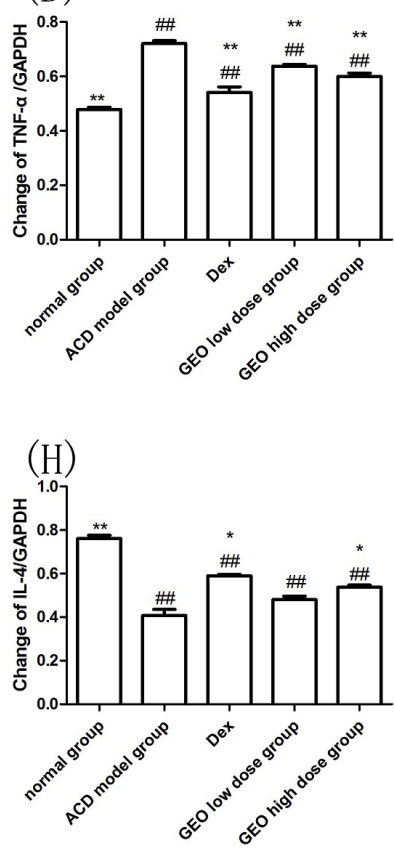

Figure 6. Effect of GEO on gene expression of inflammatory cytokines (TLR-2 (B); TLR-4 (C); TNF- $\alpha$ (D); IFN- $\gamma$ (E); IL-1 $\beta$ (F); IL-8 (G); and IL-4 (H)) of ear skin tissues of ACD mice. (A) Gray shades of resulting bands of PCR products of objective genes and reference gene evaluated by the electrophoretic image analysis system. Data are expressed as mean \pm S.D. $(n=10)$. Compared with normal group, ${ }^{\# P}<0.05 ;{ }^{\# \# P<0.01 ; C o m p a r e d ~}$ with ACD model group, ${ }^{\star} \mathrm{P}<0.05 ;{ }^{\star} \mathrm{P}<0.01$. 


\section{Conclusion}

GEO has anti-inflammatory and protective effect on chemically-induced cutaneous inflammation, which was related to the inhibitory effect on production of inflammatory cytokines such as TLR-2, TLR-4, TNF- $\alpha$, IFN- $\gamma$, IL- $1 \beta$, IL-8 and IL-4 induced by DNFB challenge. Therefore, GEO has the potential as a kind of functional components having effects of ameliorating skin inflammation.

\section{Acknowledgements}

This work was supported by Key University Natural Science Research Project of Jiangsu Province (Grant No. 16KJA550001), and the Priority Academic Program Development of Jiangsu Higher Education Institutions (PAPD).

\section{References}

Akhtar, N., Verma, K. K., \& Sharma, A. (2010). Study of pro- and anti-inflammatory cytokine profile in the patients with parthenium dermatitis. Contact Dermatitis, 63(4), 203-208. http://dx.doi. org/10.1111/j.1600-0536.2009.01693.x. PMid:20698862.

Ding, Z. X., Qian, G. C., \& Zhang, Q. (2013). Effects of Xuemaitong granules on monocytes TLR-4,IL-6 and TNF- $\alpha$ in apo E-deficient mice with atherosclerosis. Shandong Medicine, 53, 4-6.

D’Mello, C., Le, T., \& Swain, M. G. (2009). Cerebral microglia recruit monocytes into the brain in response to tumor necrosis factora signaling during peripheral organ inflammation. The Journal of Neuroscience, 29(7), 2089-2102. http://dx.doi.org/10.1523/ JNEUROSCI.3567-08.2009. PMid:19228962.

Gaffal, E., Cron, M., Glodde, N., \& Tuting, T. (2013). Anti-inflammatory activity of topical THC in DNFB-mediated mouse allergic contact dermatitis independent of CB1 and CB2 receptors. Allergy, 68(8), 994-1000. http://dx.doi.org/10.1111/all.12183. PMid:23889474.

Hausmann, M., Kiessling, S., Mestermann, S., Webb, G., Spöttl, T., Andus, T., Schölmerich, J., Herfarth, H., Ray, K., Falk, W., \& Rogler, G. (2002). Toll-like receptors 2 and 4 are up-regulated during intestinal inflammation. Gastroenterology, 122(7), 1987-2000. http://dx.doi. org/10.1053/gast.2002.33662. PMid:12055604.

Huang, X. S., Wang, J. H., \& Lu, S. F. (1997). Study on antioxidant activity of ginger. Science and Technology of Food Industry, 4, 16-17.

Jeena, K., Liju, V. B., Viswanathan, R., \& Kuttan, R. (2014). Antimutagenic potential and modulation of carcinogen-metabolizing enzymes by ginger essential oil. Phytotherapy Research, 28(6), 849-855. http:// dx.doi.org/10.1002/ptr.5064. PMid:24023002.
Lei, H., Li, X. L., Wei, Q. N., Zhou, R. J., \& Wu, J. (2016). Extractions and purification of ginger essential oil by supercritical carbon dioxide combined with macroporous resin method. Current Topics in Nutraceutical Research, 14, 59-66.

Li, J., Liu, Y., Dong, L., Yue, W. J., Huang, J. P., Jiang, W. R., Sun, X., Zhong, L., \& Liu, J. (2010). Preventive effects of TLR2 monoclonal antibodies and TLR4 monoclonal antibodies on the colonal mucosal inflammatory cytokines (IFN- $\gamma$,IL-4 and IL-17) expression in mice with DSS-induced acute ulcerative colitis. Fudan University Journal of Medical Sciences, 37, 253-258.

Malu, S. P., Obochi, G. O., Tawo, E. N., \& Nyong, B. E. (2009). Antibacterial activity and medicinal properties of ginger (Zingiber officinale). Global Journal of Pure and Applied Sciences, 15(3-4), 365-368. http:// dx.doi.org/10.4314/gjpas.v15i3-4.48561.

Medzhitov, R. (2011). Toll-like receptors and innate immunity. Nature Reviews. Immunology, 1(2), 135-145. http://dx.doi.org/10.1038/35100529. PMid:11905821.

Pan, Q. J., Liu, Y., Zhu, P., Hou, X. R., \& Liu, Y. J. (2012). The inhibition of antibodies against mouse TLR2 extracellular domain on the inflammation and allergic response induced by agonists of TLR2. Chinese Journal of Immunology, 28, 685-689.

Penna, S. C., Medeiros, M. V., Aimbire, F. S. C., Faria-Neto, H. C. C., Sertie, J. A. A., \& Lopes-Martins, R. A. B. (2003). Anti-inflammatory effect of the hydralcoholic extract of Zingiber officinale rhizomes on rat paw and skin edema. Phytomedicine, 10(5), 381-385. http:// dx.doi.org/10.1078/0944-7113-00271. PMid:12834002.

Shukla, Y., \& Singh, M. (2007). Cancer preventive properties of ginger: a brief review. Food and Chemical Toxicology, 45(5), 683-690. http:// dx.doi.org/10.1016/j.fct.2006.11.002. PMid:17175086.

Wang, C., Yuan, J., Wu, H. X., Chang, Y., Wang, Q. T., Wu, Y. J., Zhou, P., Yang, X. D., Yu, J., \& Wei, W. (2015). Total glucosides of paeony inhibit the inflammatory responses of mice with allergic contact dermatitis by restoring the balanced secretion of pro-/anti-inflammatory cytokines. International Immunopharmacology, 24(2), 325-334. http://dx.doi.org/10.1016/j.intimp.2014.12.026. PMid:25556068.

Wang, Q. B., Sun, L. Y., Gong, Z. D., \& Du, Y. (2016). Veratric acid inhibits LPS-induced IL-6 and IL-8 production in human gingival fibroblasts. Inflammation, 39(1), 237-242. http://dx.doi.org/10.1007/ s10753-015-0243-9. PMid:26329367.

Young, H. Y., Luo, Y. L., Cheng, H. Y., Hsieh, W. C., Liao, J. C., \& Peng, W. H. (2005). Analgesic and anti-inflammatory activities of [6]-gingerol. Journal of Ethnopharmacology, 96(1-2), 207-210. http:// dx.doi.org/10.1016/j.jep.2004.09.009. PMid:15588672.

Zhou, F. (2009). Molecular mechanisms of IFN-gamma to up-regulate MHC class I antigen processing and presentation. International Reviews of Immunology, 28(3-4), 239-260. http://dx.doi. org/10.1080/08830180902978120. PMid:19811323. 